\title{
O Sofrimento Mental entre Adolescentes e os Benefícios Através da Arte
}

\section{The Mental Suffering Among Teenagers and the Benefits Of Art}

\section{Sufrimiento Mental Entre Adolescentes y los Beneficios del Arte}

\author{
iD (9) \\ Mariana Ávila Ferreira \\ Uniderp \\ D Erlinda Martins Batista \\ Universidade Federal de Mato Grosso do Sul \\ iD 9 \\ Edna de Souza Olive \\ Universidade Federal de Mato Grosso do Sul
}

Resumo: O sofrimento mental é prevalente durante a adolescência, no entanto, o uso da Arte está em ascensão como atividade para amenizar este problema. Logo, o artigo objetivou analisar a realização de Oficinas de Arte para detectar a ocorrência de sofrimento mental em adolescentes de uma escola pública, analisando também os benefícios resultantes da participação na Oficina. No âmbito da extensão universitária, houve compartilhamento do conhecimento adquirido e o desenvolvimento da realidade social da escola. Na perspectiva qualitativa, tabulou-se e categorizou-se os dados sob a teoria da análise de conteúdo. As análises fundamentam-se na teoria da interação de Vygotsky, e apontam quatro entre sete estudantes com sofrimento mental. Além de que a Oficina de Arte gerou os seguintes benefícios: "superação", "expressividade", "discernimento" e "tranquilidade". Assim, o estudo fortalece a ação 
social e promove a relação universidade e comunidade, no tripé; ensino, pesquisa e extensão.

Palavras-chave: Extensão. Pesquisa. Ensino. Medicina.

Abstract: The mental suffering is prevalent during adolescence, however, the use of Art is in constant rising as activity to alleviate the mental suffering. Therefore, this paper has aimed to conduct Art Workshops, in teenagers from a public school, to analyze the mental suffering and the benefits from the Art Workshop. In the scope of an academic extension, there was some sharing about the acquired knowledgement and the development of the social reality of the school. From a qualitative perspective, data were tabulated and categorized under the theory of content analysis. The analyzes are based on Vygotsky's theory of interaction, and point out four out of seven students with mental suffering. Besides that the Art Workshop generated the following benefits: overcoming, expressiveness, discernment and tranquility. Thus, the study strengthens social action and promotes the relationship between university and community, on the tripod; teaching, research and extension.

Keywords: Extension. Search. Teaching. Medicine.

Resumen: El sufrimiento mental prevalece durante la adolescencia. Sin embargo, el uso del Arte está en constante ascenso como actividad para aliviar el sufrimiento mental. De esa manera, el artículo tuvo como objetivo, analizar la realización de Talleres de Arte para detectar la ocurrencia de sufrimiento mental en adolescentes de una escuela pública, analizando también los beneficios resultantes de la participación en el Taller. En el ámbito de la extensión universitaria, se compartió el conocimiento adquirido y el desarrollo de la realidad social de la escuela. En una perspectiva cualitativa, los datos fueron tabulados y categorizados bajo la te- 
oría del análisis de contenido. Los análisis se basan en la teoría de la interacción de Vygotsky y señalan que cuatro de cada siete estudiantes tienen sufrimiento mental. Además, el Taller de Arte generó los siguientes beneficios: "superación", "expresividad", "discernimiento" y "tranquilidad". Así, el estudio fortalece la acción social y promueve la relación entre universidad y comunidad, sobre el trípode; docencia, investigación y extensión.

Palabras clave: Extensión. Investigación. Docencia. Medicina.

Data de submissão: 05/11/2020

Data de aprovação: 26/11/2020

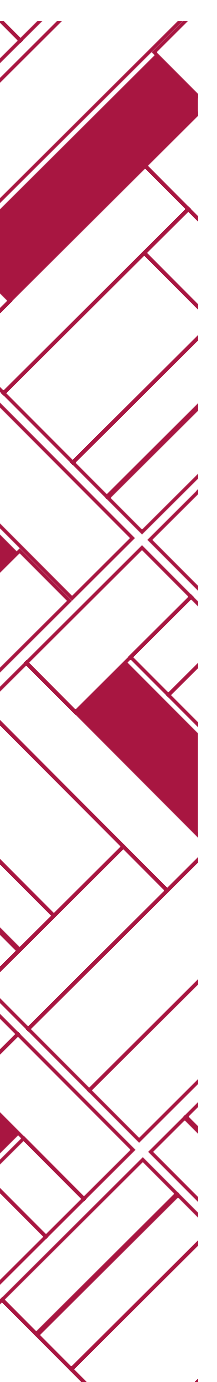


Jornal Escolar e Compromisso Social em Tempos Pandêmicos:

A Experiência do Projeto Folha Cefet

Andreza Barboza Nora • Ana Letícia Couto Araujo, et el...

\section{Introdução}

A adolescência é uma fase de intensos conflitos e mudanças, em que o sofrimento mental e a depressão são vistas como um problema crescente. Também é importante ressaltar que o sofrimento mental, na adolescência, é uma das principais causas de morbidade e mortalidade, e está correlacionado com a dificuldade de criar vínculos interpessoais (BROCHADO; 2008). Além disso, a depressão pode ter como consequência o suicídio, sendo a segunda principal causa de morte acometendo os adolescentes (WORLD, 2016).

De acordo com Levy (2007), tal período pode se tornar traumático ou patológico, quando o sujeito não consegue representar os seus sentimentos dessa nova fase, que é a adolescência. Portanto, ainda é necessário medidas preventivas e formas de amenizar o sofrimento mental, visto que a Reforma Psiquiátrica regulamenta a prevenção acima da cura (BRASIL, 2004). E, assim, surgem as oficinas terapêuticas que podem ser consideradas atividades grupais de vários conteúdos, com o objetivo de promover maior expressividade e integração social; favorecendo, portanto, o processo de reabilitação psicossocial. (BRASIL, 2004).

Diante do objetivo de prevenir ao invés de curar, pode ser citado diversos fatores protetores para o sofrimento mental. Um fator que se considera relevante e está em constante ascensão é o uso da Arte como atividade de terapia, de prevenção e reabilitação. Esse fator ocupa, atualmente, um papel de destaque entre as atividades terapêuticas oferecidas nos Centros de Atenção Psicossocial - CAPS (BRASIL, 2004).

Portanto, a Arte foi escolhida como ferramenta, porque esse recurso expressivo ajuda a desenvolver maiores habilidades de 
Jornal Escolar e Compromisso Social em Tempos Pandêmicos:

A Experiência do Projeto Folha Cefet

Andreza Barboza Nora • Ana Letícia Couto Araujo, et el...

comunicação, além de encorajar os pacientes a desenvolver uma autoimagem positiva (CANUTO et al., 2008). Além disso, Porcher (1982, p. 30) complementa que “[...] Não há dúvida de que a prática das atividades artísticas representa um fator altamente favorável para o desenvolvimento de toda a personalidade e, especialmente, dos seus aspectos intelectuais".

Logo, este artigo, realizado no âmbito da pesquisa científica, do ensino e da extensão universitária, objetivou analisar a realização de Oficinas de Arte para detectar a ocorrência de sofrimento mental em estudantes adolescentes de uma escola pública do Estado de Mato Grosso do Sul, mais precisamente do Ensino Médio, analisando também os benefícios resultantes da participação na Oficina citada, a fim de compartilhar o conhecimento e transformar a realidade escolar dos alunos. Portanto, se constitui em uma ação relevante no contexto da interação entre universidade e escolas da comunidade, pois essa ação representa a integração almejada pela extensão universitária, a qual faz parte do papel da universidade ao se considerar o tripé: ensino, pesquisa e extensão.

Esse tripé se constitui a base desta pesquisa, visto que a articulação destes propicia o desenvolvimento científico. Diante disso é possível produzir mudanças, tanto no processo de ensino dos professores da referida escola, quanto no processo de aprendizagem dos alunos. Assim ocorre também a democratização do saber acadêmico e o retorno desse saber à universidade.

Logo, através da implementação da Arte como atividade para amenizar o sofrimento mental, essas ações também contribuem para elevar o índice IDEB (Índice de Desenvolvimento da Educação Básica) da escola. Considerando que o problema é recorrente e preocupante na adolescência, haja vista a crescente ocorrência de suicídios na sociedade brasileira, justifica-se o estudo. 


\section{Metodologia}

Este trabalho foi originado do projeto intitulado: "Prevenção da depressão em estudantes de uma Escola Pública Estadual de Campo Grande - MS: Oficinas de arte e habilidades médicas", aprovado no Programa Institucional de Bolsas de Iniciação Científica - PIBIC, do Conselho Nacional de Desenvolvimento Científico e Tecnológico- CNPq, conforme Edital 016/2019, de uma universidade privada, concedida à autora desse trabalho, pesquisadora e graduanda do curso de Medicina. O projeto obteve aprovação no Comitê de Ética e Pesquisa - CEP em fevereiro de 2020, com o parecer de número 3.831.920/CEP.

Em uma perspectiva qualitativa, após a aprovação do projeto pelo Comitê de Ética, a pesquisa se desenvolveu em cinco etapas principais. A primeira etapa iniciou-se a partir do levantamento bibliográfico realizado em três bases de dados. Portanto, no presente artigo são analisados os resultados alcançados a partir das pesquisas e consultas nas seguintes bases de dados utilizadas: BIREME, Scielo e PubMed.

$\mathrm{Na}$ etapa seguinte organizou-se a realização da Oficina de Arte. No detalhamento das atividades de pesquisa, foi planejada a realização de uma Oficina de Arte em uma Escola Pública Estadual de Campo Grande - MS, a qual foi realizada na primeira semana de março de 2020, no período vespertino. Antes da realização da oficina, foi divulgado um Flyer (cartaz online que também foi impresso e afixado no mural da referida escola) contendo uma chamada aos estudantes do ensino médio para a participação. Também foi decidido como critério de inclusão, que a inscrição seria aberta aos alunos interessados do $1^{\circ}$ ao $3^{\circ}$ ano do Ensino Médio. Já o critério de exclusão estabeleceu-se para os alunos que não assinaram 
Jornal Escolar e Compromisso Social em Tempos Pandêmicos:

A Experiência do Projeto Folha Cefet

Andreza Barboza Nora • Ana Letícia Couto Araujo, et el...

o Termo de Assentimento Livre e Esclarecido - TALE, ou que os responsáveis não assinaram o Termo de Consentimento Livre e Esclarecido - TCLE.

A terceira etapa, portanto, foi subdivida em quatro momentos, a seguir detalhados. Sobre a Oficina, no primeiro momento houve uma dinâmica de apresentação dos participantes, para a qual foi orientada a confecção de um crachá personalizado, com imagens que representassem os gostos e interesses dos alunos e sua concepção de identidade, respondendo à pergunta: “Quem sou eu?". No segundo momento aplicou-se um primeiro questionário e, em seguida, no terceiro momento, orientou-se aos estudantes que utilizassem os materiais fornecidos a eles, tais como: quadros, pincéis e tintas para a elaboração de quadros de pinturas, que expressassem seus sentimentos. Ao concluírem as pinturas, no quarto momento da oficina, os estudantes foram convidados a participar de uma roda de conversa, para a exposição de suas percepções e sentimentos sobre a oficina como um todo, além de responderem um segundo questionário. Nesse momento eles expressaram os seus sentimentos em relação ao que desenharam e pintaram.

Por fim, na quarta etapa da pesquisa foram trabalhados e analisados os resultados obtidos com a aplicação dos questionários. O primeiro questionário aplicado é denominado Self-Reporting Questionnaire 20 (SRQ-20), é um teste que rastreia o sofrimento mental, composto por vinte itens, sendo as respostas do tipo sim/ não. A partir de cada resposta positiva se pontua um ponto para compor o score final, que é obtido por meio do somatório desses valores (GONÇALVES; STEIN; KAPCZINSKI, 2008). Vale ressaltar que com no mínimo sete respostas positivas comprovam-se sofrimento mental. Porém, é importante notar que o diagnóstico definitivo é fornecido apenas por um profissional da área. 
Jornal Escolar e Compromisso Social em Tempos Pandêmicos:

A Experiência do Projeto Folha Cefet

Andreza Barboza Nora • Ana Letícia Couto Araujo, et el...

Já referente ao segundo questionário, do tipo semiaberto, elaborado através das próprias autoras para análise neste artigo, escolheu-se duas questões. Uma referente ao sentimento dos alunos após a oficina e a outra sobre os benefícios que os discentes observaram após a participação na oficina. Os dados coletados pela aplicação dos questionários foram tabulados de acordo com o método de categorização de Bardin (1977).

De acordo com Bardin (1977), a categorização classifica elementos por diferenciação e, seguidamente, por reagrupamento segundo o gênero, com os critérios previamente definidos. Logo, esse método visou agrupar os benefícios trazidos segundo os depoimentos dos estudantes participantes na oficina, selecionando a essência do discurso de cada participante.

A abordagem utilizada foi a de pesquisa qualitativa em educação, segundo Bogdan e Biklen (1982), visto que o estudo qualitativo tem como benefício capturar a perspectiva dos participantes, para que assim se analise a importância e significado que as pessoas dão às coisas. Nesse caso, o significado que os estudantes dão às atividades realizadas em forma de desenhos durante a referida Oficina de Arte.

Além desses, também se utilizou a perspectiva histórico-cultural, de acordo com Vygotski (2004), para fundamentar as análises que discutem a educação do comportamento emocional.

Vale ressaltar que até o segundo momento a oficina contou com a presença de sete estudantes do terceiro ano do ensino médio, entretanto três desistiram de continuar a oficina, e foram embora logo após a aplicação do SRQ-20, isso é, esses três não participaram da elaboração das atividades artísticas para a expressão de seus sentimentos e não responderam o segundo questionário, que compuseram o terceiro e quarto momento da Oficina. 
Jornal Escolar e Compromisso Social em Tempos Pandêmicos:

A Experiência do Projeto Folha Cefet

Andreza Barboza Nora • Ana Letícia Couto Araujo, et el...

Por fim, na quinta fase da pesquisa foram realizadas as análises sobre a fundamentação das teorias mencionadas, tendo essa fase gerado o presente artigo.

\section{Atividade de extensão}

A extensão universitária além de permitir a formação de um profissional atento às demandas biopsicossociais da comunidade, também permite transformar a realidade social do meio no qual vive. Portanto, a presente Atividade de Extensão, ancorada ao PIBIC, focou em realizar Oficina de Arte com o intuito de detectar sofrimento mental em estudantes adolescentes. Isso ocorreu a partir da integração do conhecimento tanto de docentes e discentes da universidade, quanto do conhecimento de docentes da referida escola, a saber; uma coordenadora pedagógica, colaboradora no artigo.

Segundo Carbonari e Pereira (2007), a extensão universitária se depara com um grande desafio: adequar a relação do ensino e da pesquisa às necessidades sociais. Partindo deste pressuposto, a atividade desenvolvida com os adolescentes estabeleceu um vínculo do conhecimento de uma Acadêmica de Medicina, de uma Doutora em Educação e de uma Especialista em Arte Educação, para a colocação de seus trabalhos a serviço dos interesses da comunidade, visando discutir que tipo de interação e atividades do campo da arte podem contribuir para melhorar a qualidade de vida dos adolescentes com sofrimento mental e intencionalmente produzir a transformação da realidade escolar, familiar e pessoal destes estudantes.

Para isso, o planejamento da atividade em extensão foi dividido em quatro momentos principais: estudo do local, preparação metodológica, intervenção da realidade social e oferecimento de um seminário à comunidade escolar sobre os resultados encontrados, no sentido de efetivar a ação social de extensão universitária. 
Jornal Escolar e Compromisso Social em Tempos Pandêmicos:

A Experiência do Projeto Folha Cefet

Andreza Barboza Nora • Ana Letícia Couto Araujo, et el...

O primeiro passo, que corresponde ao estudo da escola, foi importante para a percepção da realidade social. A escola estadual obteve pontuação de 5,1 no Índice de Desenvolvimento da Educação Básica - IDEB, e para melhorar essa classificação a escola precisava desenvolver estratégias no sentido de aprimorar a qualidade do ensino, porém deparava-se com o sofrimento mental principalmente entre alunos do $1^{\circ}$ ao $3^{\circ}$ ano do Ensino Médio. A escola enfrentava casos de adolescentes que praticavam automutilação e também recebia relato familiar de estudantes com pensamento suicida.

Em um segundo momento houve a preparação metodológica, detalhada anteriormente, com o objetivo primeiramente de criar um vínculo com os adolescentes, para que posteriormente estivessem à vontade para expressarem suas emoções em forma de pintura e falassem abertamente sobre seus sentimentos e angústias. Logo, a metodologia também foi pensada para conhecer melhor a realidade destes estudantes e propiciar uma integração efetiva entre universidade e escola da comunidade.

Em um terceiro momento houve a intervenção na realidade local, que foi a realização da Oficina de Arte com a intencionalidade de ação social. Diante de um público com considerável sofrimento mental e da integração da extensão-ensino-pesquisa, o objetivo foi transformar a realidade social escolar e estudantil, a partir de um "feedback" para o corpo docente da escola, famílias e adolescentes.

Tal feedback compõe o quarto e último momento da pesquisa, sob a forma da realização de um seminário para professores e comunidade escolar, no qual foram apresentados os resultados alcançados com a realização da oficina, bem como os estudos sobre a interação realizada.

Portanto, as ações pedagógicas e de extensão envolvendo a arte e a pesquisa, passam a ser instrumentos que contribuem 
Jornal Escolar e Compromisso Social em Tempos Pandêmicos:

A Experiência do Projeto Folha Cefet

Andreza Barboza Nora • Ana Letícia Couto Araujo, et el...

para novas decisões no âmbito da coordenação e práticas pedagógicas, cujo produto final espera-se, promova o autoconhecimento e desenvolvimento interativo entre adolescentes, e entre esses estudantes e professores, o que a partir disto, conforme a teoria da interação de Vygotsky (2004), se constitui em papel incomensurável dos professores e da escola, pois, esses organizam as atividades cognitivas, que em decorrência, organizam as emoções, levando-os a adaptar-se à fase de profundas transformações na qual se inserem.

Logo, a Arte passou a ser abordada como um instrumento que contribui para o autoconhecimento do adolescente, que a partir disto passa a lidar com as emoções e adaptar-se à fase na qual vive.

\section{Interlocução com vygotsky sobre a educação emocional}

Na teoria Vygotskyana (2004, p. 128), o ser humano se constitui da ontogênese, cuja raiz está na sua natureza biológica e origem das suas relações com o meio que são possíveis, a partir de suas funções psíquicas superiores, definindo-se, assim, a sua natureza psicológica. As reações que se originam em sua natureza biológica produzem emoções caracterizadas pelo seu aspecto biológico.

As emoções podem ser expressas a partir dos sentimentos separados em três grupos: 1) movimentos pantomímicos (das contrações especiais dos músculos, principalmente dos olhos, da boca, das maçãs do rosto e das mãos), "Há aí uma classe das reações - emoções - motoras"; 2) reações somáticas, em que há uma mudança na atividade de alguns órgãos que se relacionam às funções vitais do organismo, tais como: respiração, os batimentos cardíacos e a respiração sanguínea; e 3) reações secretórias de ordem interna e externa, como as lágrimas, o suor, a salivação e a secreção interna das glândulas sexuais (VYGOTSKY, 2004, p.128). 
Jornal Escolar e Compromisso Social em Tempos Pandêmicos:

A Experiência do Projeto Folha Cefet

Andreza Barboza Nora • Ana Letícia Couto Araujo, et el...

Com relação às emoções que se originam na natureza psicológica, Vygotsky (2004, p. 135) defende que “(...) o comportamento é um processo de interação entre o organismo e o meio". E nesse processo é possível haver três correlações que se alternam uma com as outras: 1) o organismo sente a sua superioridade sobre o meio, nessa situação o organismo realiza sua adaptação ao meio em nível excelente e com o mínimo de dispêndio de energia e forças; 2) o meio detém a superioridade e a supremacia, nesse caso o organismo busca adaptar-se à dificuldade com excessiva tensão e há uma disparidade entre a complexidade do meio e a defensividade fraca do organismo, havendo, então, a máxima perda de forças, o máximo dispêndio de energia e o mínimo efeito de adaptação do organismo ao meio; e 3) equilíbrio entre o organismo e o meio, no qual não há disputa e nenhuma das partes tem supremacia sobre a outra.

Segundo Vygotsky (2004, p. 136), em todos esses três casos há base para o desenvolvimento do comportamento emocional. Na visão desse teórico, as reações emocionais são organizadoras internas do comportamento e das funções psíquicas superiores. São alavancas que propiciam o desenvolvimento do indivíduo e, ainda segundo o teórico, "as emoções seriam inúteis se não fossem ativas" (VYGOTSKY, 2004, p.137). Assim, todas as emoções dos estudantes investigados são úteis para o seu desenvolvimento. Todas as suas emoções, sem exceção, são organizadoras de seu comportamento e, em consequência, de seu desenvolvimento emocional.

Portanto, a organização do meio educativo, com atividades que estimulam a transferência das emoções, e nas quais haja interação, como a arte, é o passo fundamental que o professor precisa dar para a educação dos sentimentos de estudantes que vivenciam tensões em seu cotidiano familiar e social. 
Jornal Escolar e Compromisso Social em Tempos Pandêmicos:

A Experiência do Projeto Folha Cefet

Andreza Barboza Nora • Ana Letícia Couto Araujo, et el...

\section{Resultados}

Os resultados da tabulação dos dados mostraram que, no contexto aplicado, $57 \%$ dos estudantes participantes da Oficina de Arte apresentam sofrimento mental. O Gráfico 1, a seguir, ilustra esse fato.

Gráfico 1: Número de alunos que apresentaram sofrimento mental, segundo o SRQ-20.

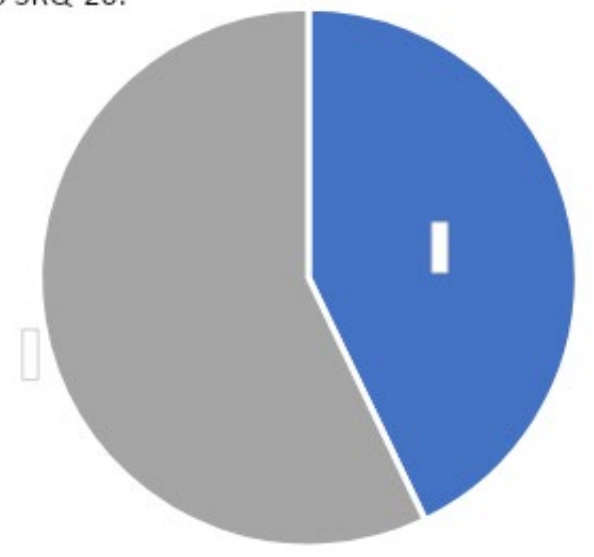

Gráfico 01.

Fonte: Autoria própria (2020).

O gráfico acima refere-se aos resultados obtidos através da aplicação do SRQ-20 e estão em concordância com os dados da Organização Mundial de Saúde (OMS, 2003), visto que a nível mundial demonstrou que cerca de $20 \%$ de crianças e adolescentes apresentam algum problema de saúde mental. Essa situação deve ser observada com cautela, tendo em vista que pode trazer consequências negativas, a curto e longo prazo, nas trajetórias de desenvolvimento dos indivíduos.

No contexto da Oficina de Arte realizada, observa-se que apenas $43 \%$ dos estudantes participantes das atividades não apresentaram sofrimento mental. Esse dado é relevante, pois considera que os demais $57 \%$ dos estudantes sofrem com o sofrimento mental nesse ambiente. A interação nas atividades lúdicas, como a 
Jornal Escolar e Compromisso Social em Tempos Pandêmicos:

A Experiência do Projeto Folha Cefet

Andreza Barboza Nora • Ana Letícia Couto Araujo, et el...

da oficina de arte, pode ser um benefício para a prevenção desse problema, na medida em que o sujeito se sente acolhido, atendido e suas funções psíquicas superiores se desenvolvem resultando em reações emocionais favoráveis à sua aprendizagem e sentimentos de pertencimento, conforme afirma Vygotsky (2004) sobre as reações emocionais e adaptação ao meio, a partir da interação que se realiza nas relações com as pessoas e com o meio.

Como a adolescência é uma fase de intensos conflitos, há a necessidade de se atentar para as dificuldades nesse período, ou seja, para as oscilações de humor, para a tendência em assumir comportamentos de risco e para o número aumentado de embates familiares intensos (CICCHETTI; ROGOSH, 2002). Diante desse cenário, os adolescentes com transtornos mentais podem apresentar prejuízo em assimilar as tarefas diárias correspondentes a sua idade (FLOREY, 2002). Portanto, a vida do estudante, como um todo, se vê prejudicada. Principalmente com a grande dificuldade em demonstrar sentimentos e lidar com problemas da vida cotidiana.

Então, percebe-se que o sofrimento mental traz consequências que vão além da patologia do adolescente, atingindo todo o seu biopsicossocial. Por isso, há a necessidade de uma abordagem que envolva o adolescente, sua família, a sociedade e os serviços de apoio. E é justamente por isso que, de acordo com o Ministério da Saúde (MENDES, 2008), a rede de cuidados em saúde dos adolescentes deve ser composta por ações de saúde mental desde a Atenção Primária, até a ações que envolvam a escola, lazer, cultura e família do indivíduo. Para que, dessa forma, o adolescente seja abordado em sua forma integral, prevenindo o sofrimento mental nessa faixa etária tão prevalente.

Os resultados da Oficina sobre as emoções são mostrados no Quadro 01. 
Jornal Escolar e Compromisso Social em Tempos Pandêmicos:

A Experiência do Projeto Folha Cefet

Andreza Barboza Nora • Ana Letícia Couto Araujo, et el...

\begin{tabular}{c|l|l|l|}
\hline CATEGORIAS & $\begin{array}{c}\text { SENTIMENTO } \\
\text { APÓS OFICINA }\end{array}$ & $\begin{array}{l}\text { DISCURSO COM OS } \\
\text { BENEFÍCIOS APÓS A } \\
\text { OFICINA }\end{array}$ & $\begin{array}{l}\text { ESSÊNCIA DO } \\
\text { DISCURSO }\end{array}$ \\
\hline A1 & Felicidade & $\begin{array}{l}\text { "Sinto que posso } \\
\text { superar o passado" }\end{array}$ & Superação \\
\hline A2 & Alívio & $\begin{array}{l}\text { "Consigo expressar } \\
\text { melhor como eu me } \\
\text { sinto" }\end{array}$ & Expressividade \\
\hline A3 & Felicidade & $\begin{array}{l}\text { "Me ajudou a abrir } \\
\text { meus olhos sobre } \\
\text { minha vida" }\end{array}$ & Discernimento \\
\hline A4 & Felicidade & $\begin{array}{l}\text { "Consegui me sentir } \\
\text { tranquilo" }\end{array}$ & Tranquilidade \\
\hline
\end{tabular}

Legenda: A1/A2/A3/A4 se referem aos alunos participantes da oficina.

QUADRO 01: Respostas dos estudantes sobre suas percepções após sua participação na Oficina de Arte Fonte: Autoria própria (2020).

O Quadro 01 mostra emoções que representam benefícios importantes, isso após a realização da Oficina de Arte. Na essência do discurso, as categorias encontradas foram: superação, expressividade, discernimento e tranquilidade. Assim, na categoria: "discernimento", observa-se que o estudante afirmou encontrar a realidade, ao dizer que a oficina abriu seus olhos sobre a sua vida, portanto esse discurso sugere que a oficina, para esse estudante, possibilitou discernir e enxergar a sua vida. Discernir, nesse caso, é uma forma de observar a vida com clareza e distinção entre o que é real e o que é fantasia. Na verdade, a essência do discurso reflete muito bem as ideias de Fischer (1983), pois para o autor, a função essencial da arte é a de fazer esclarecer e incitar à ação, sendo necessária para que os indivíduos conheçam e transformem o mundo em que vivem. 
Jornal Escolar e Compromisso Social em Tempos Pandêmicos:

A Experiência do Projeto Folha Cefet

Andreza Barboza Nora • Ana Letícia Couto Araujo, et el...

Fischer (1987, p. 51-52) ainda manifesta que: "A tarefa do artista é expor ao seu público a significação profunda dos acontecimentos, fazendo-o compreender claramente a necessidade das relações essenciais entre o homem e a natureza e entre o homem e a sociedade". Em síntese, a arte se mostra como um importante instrumento para a descoberta de si mesmo e do mundo a sua volta.

A sociedade atual é dotada de extremos. Expressividade ou técnica, certo ou errado, tradição ou inovação (FREITAS, 2005). E, diante disso, os adolescentes se veem com dificuldade de expressar o que sentem. Portanto, a arte é usada justamente para interceder e manter um equilíbrio desses extremos; a arte é produzida por uma necessidade de expressão ou é um produto do embate homem/mundo, por isso mesmo ela é vida. Por meio dela, o homem interpreta sua própria natureza, construindo formas e ao mesmo tempo em que se descobre, se reinventa, figura-se e se conhece (BUORO, 2000, p. 25).

De acordo com Duarte Júnior (1994, p. 136), a arte está presente na vida do homem desde que este existe no mundo, foi tudo o que restou das culturas pré-históricas, porém, nem sempre valorizada durante aqueles anos. Hoje, sabe-se que a arte tem características imprescindíveis para o desenvolvimento individual e coletivo da população.

A categoria da "expressividade", justamente atribuída por um estudante participante da oficina, que afirmou conseguir se expressar melhor por meio da arte, sugere um sentimento de leveza vivenciado, ao conseguir manifestar suas emoções em seu desenho. Por esse motivo, a realização da Oficina de Arte levou os participantes a construírem um estado de autorrealização, por experimentarem, externalizarem e refletirem seus pensamentos, gerando as demais categorias: implícitas no sentimento de "tranquilidade" e na "superação" dos problemas cotidianos. (FREITAS, 2005). 
Jornal Escolar e Compromisso Social em Tempos Pandêmicos:

A Experiência do Projeto Folha Cefet

Andreza Barboza Nora • Ana Letícia Couto Araujo, et el...

A seguir são mostrados os desenhos produzidos.

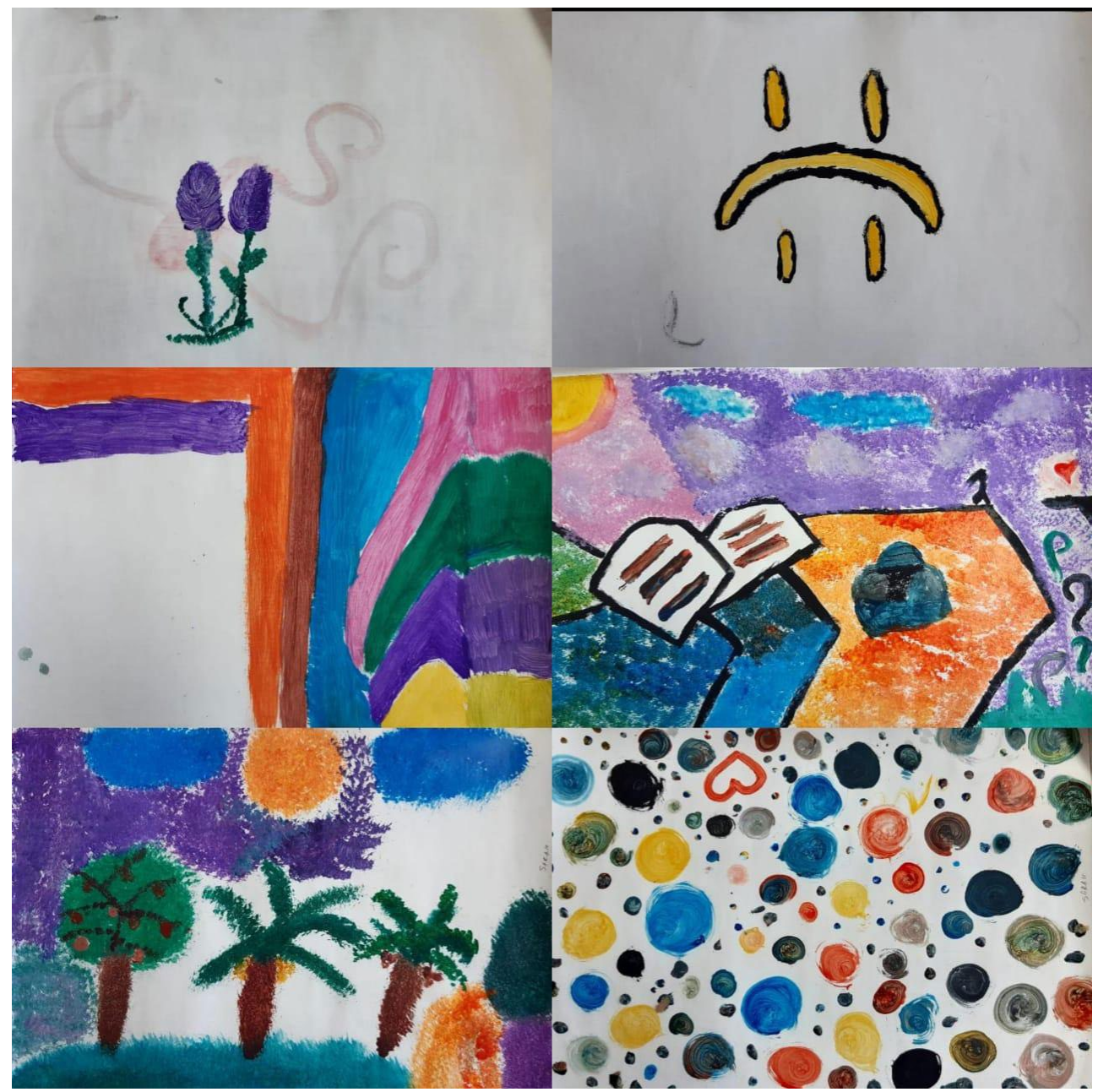

IMAGEM 01: Pinturas dos estudantes durante a Oficina de Arte

Fonte: Desenhos dos Estudantes, em ordem da esquerda para a direita: A1, A2, A3 e A4 (mar/2020); Fotografia em mosaico de autoria própria (jul/2020)

A imagem 01, fotografada a partir dos desenhos, resultando em uma imagem de estilo mosaico, ilustra os diferentes sentimentos dos adolescentes: A1, A2, A3 e A4. Visto que a arte é uma das primeiras manifestações da humanidade, pois serve como forma do ser humano representar sua experiência de vida, manifestar pensamentos e principalmente sentimentos que são difíceis de serem expressos em palavras (AZEVEDO JÚNIOR, 2007); foi a maneira empregada para que os alunos exprimissem melhor suas emoções. 
Jornal Escolar e Compromisso Social em Tempos Pandêmicos:

A Experiência do Projeto Folha Cefet

Andreza Barboza Nora • Ana Letícia Couto Araujo, et el...

O segundo desenho, contando da esquerda para a direita, foi elaborado por A2, e esse estudante afirmou que nele expressa a variação de seu estado de humor. Dependendo da posição do cartaz, se vê uma imagem de um sorriso, e se o cartaz é virado para baixo, se vê a imagem de tristeza. Conforme Vygotsky (2004), as reações emocionais do estudante $A 2$ sugere que a organização interna do seu comportamento e de suas funções psíquicas superiores se realiza a partir de seu estado de sentimento de prazer ou de dor emocional.

O quarto desenho, mostrado no centro do mosaico à direita, foi explicado por A4 como uma expressão de sua tristeza em sentir-se rejeitada por colegas de turma. Ela afirmou que sua tristeza era tão profunda que sua mãe a levou ao psiquiatra. E agora ela depende de remédios para sentir-se em equilíbrio. Todavia, ela perguntou ao final de seu depoimento: "por que minha colega não gosta de mim?" (DISCURSO DE A4, MARÇO/2020). O discurso evidencia que, nesse caso, essa estudante sente o que Vygotsky (2004) denomina de esforço de adaptação, ao sentir a supremacia do meio. Embora, A4 busque adaptar-se à dificuldade com excessiva tensão, ainda assim há uma disparidade entre a complexidade do meio e a defensividade fraca de seu organismo. O que se conclui como razão da necessidade dessa estudante utilizar remédios psiquiátricos para conseguir adaptar-se àquele meio escolar.

Logo, a arte proporcionou uma forma diferenciada de comunicação aos alunos, para que a partir de seus sentimentos estivessem livres para expressá-los em formato de pintura. Apesar de todos os sentimentos de tristeza e de dificuldades expressados pelos estudantes, verificou-se que, embora eles realizem o dispêndio de energia para adaptação ao meio, as cores alegres dos desenhos indicam que algum equilíbrio eles têm alcançado nessa disputa pela supremacia de atitudes sobre o meio, conforme as ideias de Vygotsky (2004) sobre a adaptação dos sujeitos ao meio. 
Jornal Escolar e Compromisso Social em Tempos Pandêmicos:

A Experiência do Projeto Folha Cefet

Andreza Barboza Nora • Ana Letícia Couto Araujo, et el...

Em síntese, observou-se que os discursos dos estudantes de A1 a A4, ao relatarem as emoções que buscaram desenhar, foram construídos sobre seu estado de sofrimento ao longo de sua história, não apenas escolar, mas também familiar e de suas peculiaridades de vida. Segundo Vygotsky (2004), as funções psíquicas superiores são responsáveis pelas reações emocionais no sentido da adaptação do sujeito ao meio.

Diante do número de adolescentes com sofrimento mental e dos benefícios gerados através da Oficina, este projeto de pesquisa, ensino e extensão obteve como resultado ações que amenizaram o sofrimento mental, contribuindo para a saúde emocional e mental dos estudantes; cujos benefícios transformaram a realidade escolar destes. Visto que o corpo docente, a partir das oficinas, obtiveram um "feedback" sobre os resultados, desde então, passaram a abordar a Arte de uma nova maneira, com o objetivo de amenizar os sentimentos negativos dos alunos diante da fase conflituosa que é a adolescência.

Logo, a extensão universitária propiciou a produção de conhecimento científico, e juntamente com o ensino e a pesquisa, proporcionou a disseminação de novos conhecimentos entre os alunos e professores da referida escola. Além de contribuir para uma formação contextualizada às questões da sociedade atual, no âmbito do sofrimento mental e dos adolescentes.

\section{Considerações finais}

Conclui-se que o objetivo de analisar a realização da Oficina de arte com a intencionalidade de detectar o sofrimento mental foi alcançado e os resultados comprovaram haver benefícios nessa atividade, tanto para os estudantes participantes da oficina, quanto para os professores indiretamente envolvidos no projeto. 
Jornal Escolar e Compromisso Social em Tempos Pandêmicos:

A Experiência do Projeto Folha Cefet

Andreza Barboza Nora • Ana Letícia Couto Araujo, et el...

Isso porque a pesquisa não é neutra, pois a relação entre o todo e a produção científica, se constitui uma relação dialética, de mútua relação e interação.

A partir do uso da Arte como uma ferramenta de autoconhecimento e de desenvolvimento cognitivo, na esfera da extensão universitária, este artigo permite ao discutir os resultados, inferir que 57\% dos adolescentes participantes da pesquisa apresentaram sofrimento mental, e relataram os benefícios da Arte na forma de sentimentos de tranquilidade, expressividade, discernimento e superação, conforme as análises das categorias encontradas e as análises sobre a adaptação ao meio a partir do pensamento Vygotskyano. Essas mostraram que a arte propicia o sentimento de alívio e de felicidade após a oficina, visto que por meio dos desenhos os alunos realizam uma imersão em suas próprias vidas. Esses estudantes, ao emergirem da atividade e com a prática pedagógica da roda de conversa, puderam por meio do diálogo vivenciar a emoção de superação de conflitos, os quais são recorrentes e existentes na adolescência.

A arte, através do projeto de extensão, se mostrou a chave para a autolibertação das limitações pessoais, dando a chance de tais estudantes observarem o mundo com maior discernimento e clareza, através da descoberta da sua individualidade. Assim, as atividades de arte promovem uma interação psíquica com as emoções mais profundas do sujeito, e contribuem para o seu processo de equilíbrio ao buscar adaptar-se ao meio no qual vive.

Nessa interação, o adolescente consegue expor a significação profunda dos seus sentimentos, medos e anseios, ao explicar as reações que a conduz na escolha dessa ou daquela pintura ou obra de arte. Identifica-se, por meio da pintura, que mesmo no contexto da globalização atual, na qual há uma tendência da massificação e de imposições, a arte proporciona autonomia para 
Jornal Escolar e Compromisso Social em Tempos Pandêmicos:

A Experiência do Projeto Folha Cefet

Andreza Barboza Nora • Ana Letícia Couto Araujo, et el...

a expressão e para o diálogo. O que representa benefícios e mudanças na vida humana, em especial para esses adolescentes que participaram da oficina mencionada.

Portanto, nas experiências vividas por meio das atividades de extensão, a arte se mostrou como um instrumento, sobretudo de interação, de expressão de sentimentos, discernimento, superação de problemas e tranquilidade. Provocando a transformação diante de um público adolescente que apresentou uma quantidade considerável de sofrimento mental, conforme mostraram os resultados.

A realidade escolar dos estudantes, do corpo docente e da escola como um todo, pode ser transformada diante do tripé: ação de extensão, ensino e pesquisa, visto que o projeto propicia meios do corpo docente abordar de uma nova maneira o uso da Oficina de Arte, a fim de amenizar os conflitos e o sofrimento mental dos alunos, gerando benefícios e bons sentimentos a eles. Logo, o uso de ações e projetos sociais, como a oficina de arte, que valorizam a extensão universitária, em conjunto com o ensino e a pesquisa, proporcionam maneiras de melhorar a realidade escolar e pessoal dos estudantes, contribuindo também para o aumento do índice IDEB da escola. Portanto, a disseminação do conhecimento produzido a partir do projeto de extensão, leva a democratização do saber acadêmico, escolar e docente.

Espera-se que este estudo contribua para novas pesquisas sobre o sofrimento mental e a superação desses problemas psíquicos em crianças e adolescentes, bem como para novos estudos sobre o uso da arte para a interação em contextos escolares. 
Jornal Escolar e Compromisso Social em Tempos Pandêmicos:

A Experiência do Projeto Folha Cefet

Andreza Barboza Nora • Ana Letícia Couto Araujo, et el...

\section{Referências}

AZEVedo junior, J.G. Apostila de Arte - Artes Visuais. São luís: Imagética COMUNicAÇÃo E DesıgN, P.59, 2007.

BARDIN, L. AnÁlise de CONTEÚdo. LISBOA: EdITORA 70, 1977.

BRASIL. Ministério da Saúde. Secretaria de Atenção à Saúde. Departamento de Ações Programáticas Estratégicas. Saúde mental no SUS: os centros de ATENÇÃO PSICOSSOCIAL. BRASÍLIA, 2004.

BOGDAN, R.C.; BIKLEN, S.K. Qualitative Research for Education. Anintroduction to theory and methods. Boston: Allyn And BaCon, 1982

BROCHADO, F; BROCHADO, A. Estudo dA PRESENÇA DE SINTOMATOLOGIA depressiva na adolescência. Revista Portuguesa de Saúde Pública, 2008. DisPONÍVEL EM: HTTPS://RUN.UNL.PT/BITSTREAM/10362/95344/1/03.PDF. ACESSO EM: 16 MAR. 2020.

22

BUORO, A. B. O OLHAR EM CONSTRUÇÃo: UMA EXPERIÊNCIA DE ENSINO E APRENdizagem da arte na escola. 4. ed. São Paulo: Cortez, 2000.

CANUTO, A. ET AL. LONGITUDINAL ASSESSMENT OF PSYCHOTHERAPEUTIC DAY HOSPITAL treatment for elderly patients With depression. Int J Geriatr Psychiatry, v. 23, N.9, P. $949,2008$.

CARBonari, Maria; PereirA, Adriana. A extensão universitária no Brasil, do assistencialísmo À sustentabilidade. São Paulo, Setembro de 2007. Base de DADOS DO ANHANGUERA.

CICCHETTI, D.; ROGOSH, F. A. A deVelopmental PSyChopathology PERSPeCtive on adolescence. Journal of Consulting and Clinical Psychology, v. 70, P.6-20, 2002.

DUARTE JÚNIOR, J. F.; Fundamentos estéticos da educação. 3. ed. CAmpinas: PAPIRUS, 1994.

FisCHeR, E. A necessidade da arte. 9. ed. Rio de Janeiro: Guanabara Koogan, 1987. 
Jornal Escolar e Compromisso Social em Tempos Pandêmicos:

A Experiência do Projeto Folha Cefet

Andreza Barboza Nora • Ana Letícia Couto Araujo, et el...

FISCHER, E. A Necessidade da Arte. Rio de Janeiro: Zahar, 1983.

FLOREY, L. DISFUNÇÃO PSICOSSOCIAL NA INFÂNCIA E ADOLESCÊNCIA. IN: NEISTADT, M. E; CREPEAU, E. B. Willard \& Spackman: terapia ocupacional. 11a ed. Rio DE JANEIRO: Guanabara KoOgan; 2002. P.580-91.

FREITAS, J. B. F de. Arte é conheCimento, é construçÃo, é expressão. Revista Digital Art\&, ANo III, n 03, ABR 2005. Disponível em: hTtP://ReVIStadigitalart. BLOGSPOT.COM/ BR. ACESSO EM: 4 ABR. 2020.

GONÇALVES, D. M; STEIN, A. T; KAPCZINSKI, F. AvaliAÇÃO DE DESEMPENHO do SELF-REPORTING QuestiONNAIRE COMO INSTRUMENTO DE RASTREAMENTO PSIQUiÁtRICO: UM ESTUdO COMPARATIVO COM O StRUCTUREd Clinical INTERVIEW FOR DSM-IV-TR. Cad. Saúde Pública, Rio de Janeiro, v. 24, N. 2, P. 380-390, FEV. 2008. DISPONÍVEL EM: HTTPS://WWW.SCIELO.BR/SCIELO.PHP?SCRIPT=SCI_ARTTEXT\&PID=S0102-311X2008000200017\&LNG=EN\&NRM=ISO. ACESSO EM 19 MAR. 2020.

23

LEVY, R. AdOLESCENCIA: EL REORDENAMIENTO SIMBÓLICO, EL MIRAR Y EL EQUILIBRIO narcisístico. Psicoanálisis, N. 29, P. 363-375, 2007.

MENDES E. V. As redes de atenção À saúde: OrganizaçÃo Pan-Americana da Saúde. Belo Horizonte: Escola de Saúde Pública de Minas Gerais, 2008.

OMS/ WORLD HEALTH ORGANIZATION. CARING FOR CHILDREN AND ADolescents With Mental disorders: Setting WHO directions. Genebra: Who GRAPHICS, 2003.

PORCHER, L. Educação artística: Luxo ou neCESsidade. 3 ed, São Paulo: Summus, 1982.

VYGOTSKY, L. S. Psicologia Pedagógica. SÃo Paulo: Martins Fontes, 2004. WORLD heAlth ORgANiZATION. Preventing suicide: A resource for media professionals. Genebra: World Health Organization, 2016. 